\title{
Book Review: Paths to a World-Class University: Lessons from Practices and Experiences
}

\author{
Edited by Nian Cai Liu, Qi Wang, and Ying Cheng. \\ Netherlands: Sense Publishers, 2011. 314 pp. \\ ISBN: 978-94-6091-353-2.
}

\begin{abstract}
Paths to a World-Class University: Lessons from Practices and Experiences is the latest volume in the Global Perspectives on Higher Education book series edited by Philip G. Altbach. The 15 chapters selected for this volume address topics related to the reasons, challenges, and best practices for the creation or improvement of world-class research universities. Editors Nian Cai Liu, Qi Wang, and Ying Cheng compile perspectives from around the world on why countries need world-class universities. The various contributions explore how institutions contribute to knowledge in respective disciplines and drive technology and economic growth in specific countries or global markets.
\end{abstract}

The book is suited for students and academics working and studying higher education, many of whom may by aspiring administrators or business leaders who are interested in understanding higher education to drive development that in turn drives innovation and business in their country to support the national economy. It is a helpful resource to those who wish to gain insight into the evolution of institutions, particularly research institutions, within higher education worldwide.

Jamil Salmi and Nian Cai Liu set the stage with an introductory chapter that cites a 1999 World Bank report identifying four key complementary components countries need in order to move to a knowledge-based economy: "an appropriate economic and institutional regime, a strong human capital base, a dynamic information infrastructure, and an efficient national innovation system" (ix). They point out that all of these dimensions are influenced by higher education. Any country desiring a strong higher education system will want a world-class university as the foundation or pinnacle of the higher education enterprise. Despite this understanding, Altbach (2004) contends that "everyone wants one, no one knows what it is, and no one knows how to get one" (para. 1).

As Altbach states, defining a world-class university is difficult. Most definitions seem to identify what resources a university has and what its outputs are, for example high-quality faculty, outstanding facilities for research, highly sought-after graduates and favorable governance. The book is comprised of 15 chapters that either explore how various institutions have evolved as world-class universities or how a country and an institution of higher learning together are attempting to build a world-class university. There is some diversity in the institutions discussed in the chapters. These institutions are spread over more than 20 nations. Some are long-established institutions and some are fairly new institutions. Some of the institutions are already ranked by Times Higher Education (THE) or Shanghai Jiao Tong University (SJTU), but most are striving toward that goal.

An institution cannot simply declare itself to be a world-class university. The distinction comes from outside the institution. The concept of ranking institutions has been ongoing for years with two main rankings-THE and SJTU-comparing institutions from around the world. Several chapters discuss the rankings and their measurements as context for the rationale for the development of a higher education institution as a world-class university. Marginson highlights the importance of the rankings in that they "create the sense of a single, common environment in education and research" (3).

The first section of the book focuses on the role of a worldclass university in a national higher education system. The first chapter by Simon Marginson sets the stage for higher education on a global scale. He delves into three dimensions of higher education for research universities: global, national and local. Marginson believes "all research universities are now immersed in processes of globalization” (3). He interviews presidents, provosts and deans of major research universities about the issues surrounding globalization of research universities within the national systems of their respective countries. This chapter provides good context from very significant educational leaders on why the world-class research university is important to their country.

Chapters 2, 3, and 4 deal with tensions that exist in the priorities at a research institution. In order to draw more resources, including money, facilities and people, many 
institutions direct their focus on upgrading their research budgets and facilities. This often places a lower priority on the education of undergraduates, although the education of undergraduates is an outcome that is important to developing countries which are trying to move toward universal education. A more educated population improves government and industry and, thus, improves the national economy.

Akiyoshi Yonezawa, in Chapter 3, provides an interesting look at the challenges facing an institution when a government wants to exercise control over a research university. He chronicles the process the Japanese government undertook to identify the "Global 30" universities in Japan. The government took stock of the positions of universities within Japan in the international rankings and desired to focus resources on 30 universities to improve their rankings and, thus, the prestige of the universities and the nation. Yonezawa points out the challenges governments experience in driving universities toward higher attainment of international rankings; the primary challenge is the uncertainty centering on defining what it means to be world class in focus. The measured quantities used to determine those rankings are always in question.

Instead of detailing the government's role in creating worldclass universities in another context, Paul Şerban Agachi and colleagues in Chapter 4 consider whether or not having a worldclass university should be a top priority for Romania. They question this primarily because of the dilemma of the multiple roles of education in Romania. Though administrators and political leaders in Romania realize the importance of improving research, they still feel an important aim of higher education is one of social cohesion. Therefore, increased access to higher education for citizens is viewed as equally important by many; but, that it is often at odds with raising admissions standards to have the type of students needed to conduct world-class research.

In Chapter 5, Natalia Ruiz-Rodgers describes the approach taken in Columbia, a challenging environment in which to build a world-class university within the context of "social strife, economic downturns and civil violence" (112). The National University in Columbia, though, is still persevering with its focus on building international recognition through internationalization, improving qualifications of faculty, funding of graduate study, increasing the number of international publications, and accreditation. Ruiz-Rodgers documents the concrete increases in each of these areas as the National University of Columbia attempts to become a world-class university.

The second section of the book focuses on institutional practices of building a world-class university. Chapters in this section reviewed the development of world-class universities in both developed and undeveloped countries. A repeat of a theme from the first section-development of world-class universities often involved larger budgets, more and better quality of researchers and better students to assist with the researchcontinues in the second section. Another common discussion point was management, particularly at the university level.

Chapter 7 by John T. Casteen III provides a very broad look at the management of universities during weak economic times. Casteen details many of the challenges facing university leadership today, challenges which center on the economic crisis: reduced funding from governments, maintenance backlogs and challenges students experience in paying tuition. These economic challenges have a major effect on attempts to increase diversity and access. While this chapter was informative in setting a context, it did not specifically address leadership guiding institutions toward world-class status.

Zé Amvela, in Chapter 8, deals with the creation of the Uniersity of Yaounde I in Cameroon. It highlights the steps taken at this relatively new university to develop itself into a worldclass university. He points to the concrete measures taken at the university to improve the quality of teaching and research, interdisciplinary research, and international cooperation. Zé Amvela also identifies specific research that the University of Yaounde I is undertaking that leaders hope will lead it to worldclass university status, as well as aid in knowledge creation that will help its citizens.

Another tension experienced within research institutions is research priorities. Chris Marlin's Chapter 10 explores the tension between a university's administration and its faculty when administration desires to focus faculty research efforts on topics and projects that it believes will improve the prestige of the institution as a world-class university. Some faculty members prefer to conduct research in their focused specialty, which leads to tension between the administration and the faculty. This issue is a more detailed view on the conflict of faculty research agendas conflicting with institution agendas, echoing discussions in Chapters 3 and 4 of the first section that discussed research agendas designed to increase international reputation of the university moving to the forefront when national governments get involved.

The National University of Singapore (NUS) is one of the highest ranked universities discussed in this book. Chapter 11 by Seeram Ramakrishna and Venni Venkata Krishna identified six factors as important to the growth of NUS as a world-class university: strong commitment for global recruitment of faculty, effective educational and research network with other leading institutions, support of building research infrastructure, development of multi-disciplinary research to address national and global issues, and positive partnerships with the private sector 
and with government policy makers. Due to this university's high ranking, it could be viewed as a model for those universities seeking best practices in improving as a world-class university.

Harold M. Maurer and Jialin C. Zheng relate how the University of Nebraska Medical Center changed its focus from a community-oriented medical center to a world-class research center. Chapter 13 walks the reader through the strategic planning process the institution undertook to make this transition.

Similarly, Jacques Lanaraès sheds light on the University of Lausanne's efforts to create a culture of excellence in its pursuit to become a world-class university. Their premise is that worldclass institutions have to deal with the same issues as any other university; they simply have to do everything to a higher standard. The university attempted to focus not only on a structure that provides mechanisms to ensure quality control, but also to develop a culture of shared beliefs and expectations and a commitment toward quality. Lanaraès provides diagrams and discusses a process to implement a culture of quality at the institution. However, there is no indication that these steps work, and he does not provide outcomes.

Moving from creating a quality culture to refining structural processes, Osama S. Tayeb and Zoheir A. Damanhouri's Chapter 15 describes the process of transforming King Abdulaziz University in Saudi Arabia into a world-class university. As with many institutions that desire to transform into a world-class university, King Abdulaziz University went through a five-year strategic planning process, focusing its efforts on improving management to improve efficiencies and quality in all its processes. It also focused on human resource development.

This is a useful book for those who want to understand the primary reasons national governments and institutions are striving to become world-class universities. It is particularly instructive to understand that for most institutions the metamorphosis involves an increase in research focus and capacity. However, many of the chapters are clear to point out that there are competing goals of higher education, such as improving the citizenry, be it for social cohesion or improving the work force in a knowledge-based economy. Also, many institutions feel compelled to provide resources and support to local and regional people and businesses. These priorities, if focused on robustly, require resources that could be directed toward improving quality of faculty or research facilities.

There are several solid chapters that provide concrete steps that an institution can consider implementing to become a worldclass university. Several chapters are brief case studies that provide readers a slightly more diverse view of how institutions are attempting to transform, but they have little in the way of concrete best practices. On the whole, this is a worthwhile book to help readers who may have limited experience with how higher education institutions in other countries are transforming. It is most helpful to understand that it is a universal issue that the challenges of universal access to education may oppose increases in research focus.

Reviewed by David McFarland
University of Pittsburgh, USA

\section{Reference}

Altbach, Philip G. 2004, January-February. "The Costs and Benefits of World-Class Universities.” Academe Online 90 (1). Washington, DC: American Association of University Professors. Available online at: http://www.aaup.org. 